\title{
Acute toxoplasmosis infection in a patient with ankylosing spondylitis treated with adalimumab: a case report
}

\author{
Toxoplasmosi acuta in un paziente con spondilite anchilosante \\ trattato con adalimumab: caso clinico
}

\author{
V.F. Azevedo ${ }^{1}$, C.F. Pietrovski ${ }^{2}$, M. de Almeida Santos $\mathbf{J r}^{2}$ \\ ${ }^{1}$ Hospital de Clínicas, Federal University of Paraná, Brazil; \\ ${ }^{2}$ Federal University of Paraná, Brazil
}

\begin{abstract}
RIASSUNTO
Viene presentato un caso di toxoplasmosi acuta in un paziente di 36 anni affetto da spondilite anchilosante inveterata trattato con adalimumab e una revisione della letteratura al rispetto.

Il caso clinico descritto sottolinea il rischio di infezione opportunista acuta concomitante all'uso di anti-TNFe l'importanza del sospetto clinico in questi casi.
\end{abstract}

Reumatismo, 2010; 62(4):283-285

\section{INTRODUCTION}

\begin{abstract}
A nkylosing spondylitis (AS) is a chronic inflammatory disease that affects the axial skeleton, often beginning in the sacroiliac joints, but accompanied also by other signs, including enthesitis, lung fibrosis and eye involvement. AS generally occurs in the second or third decade of life with inflammatory low back pain and has a strong relation with HLA-B27.

The objective of the treatment until the end of the 90's was to ameliorate pain and stiffness and preserve function (1). Nonselective nonsteroidal antiinflammatory drugs (NSAIDs), cyclooxygenase-2 selective inhibitors, and nonpharmalogic interventions, such as physiotherapy, exercise, education, and lifestyle modifications were the basis of the management. Therapy with agents like sulphasalazine was administered for peripheral arthritis $(1,2)$.
\end{abstract}

Indirizzo per la corrispondenza: Prof. Valderilio Feijó Azevedo Rua Lamenha Lins 1110 ap 11a Rebouças- Curitiba-Paraná Brazil - CEP 80250-020

E-mail: valderilio@ hotmail.com
The introduction of anti-TNF agents such as infliximab, etanercept and adalimumab was a great step towards control of the disease (3). Despite the good results, anti-TNF alpha therapy has a number of contraindications and side effects, especially when used in combination with classical immunosuppressive agents or corticosteroids. Areas of concern include opportunistic infections, malignancies, and miscellaneous complications, such as injection/infusion reactions and autoimmunity, and contraindications, such as heart failure and acute infectious diseases. Other paradoxical new adverse effects are recognized, i.e. exacerbation or development of new onset psoriasis. Although toxoplasmosis is one of the opportunistic infections, reactivation of latent tuberculosis remains the most important safety issue of anti-TNF therapies (3).

\section{CASE REPORT}

A 36-year-old white man with a 12-year history of HLA B27 positive ankylosing spondylitis (AS) with no history of uveitis or gastrointestinal symptoms was treated in our spondylarthropathies clinic because of inflammatory low back pain and peripheral involvement. He had been treated with 
NSAIDs, methotrexate and sulphasalazine since 1998, with little improvement in axial and peripheral complaints.

In November 2006, treatment with adalimumab $40 \mathrm{mg}$ every other week was started. BASDAI was 7.2 , erythrocyte sedimentation rate (ESR) $7 \mathrm{~mm} / \mathrm{h}$ and CRP 2,2 $\mathrm{mg} / \mathrm{dl}$. The patient denied previous history or known exposure to tuberculosis, purified protein derivative (PPD) was negative and chest radiograph was normal.

In October 2008, 23 months after the beginning of the treatment, he developed cervical and axillary lymphadenomegaly, malaise and headache. There was no low back pain, joint complaints or fever. BASDAI was 3,2. Adalimumab was discontinued and laboratory tests performed: hemoglobin was $14,3 \mathrm{~g} / \mathrm{dl}$, white blood cells 10,900 per microliter, ESR $2 \mathrm{~mm} / \mathrm{h}$. Liver function, renal function, and urinalysis were normal. Tests for HIV and EpsteinBarr virus (EBV) were negative. Serology for cytomegalovirus (CMV) was positive for $\mathrm{IgG}$ fraction. Serology for toxoplasma gondii (TG) disclosed a positive $\operatorname{IgM}$ titer and a negative IgG titer. Chest radiographs, head CT scan, and ophthalmologic examination were all normal.

Based on this investigation, a diagnosis of acute toxoplasmosis was suggested and treatment with sulfamethoxazole/trimethoprim and spiramycin, recommended by the infectologist, was started. One week later lymphadenomegaly improved and, after two months, there was complete resolution of the symptoms.

Serology for Toxoplasma gondii disclosed negative IgM titer and a slightly positive IgG titer. We reintroduced adalimumab subcutaneously every other two weeks three months after the complete resolution of the symptoms. Six months after the beginning of adalimumab therapy, the patient was well and without severe AS activity or signals/symptoms of toxoplasmosis.

\section{DISCUSSION}

TG is an obligate intracellular parasite that infects up to a third of the world's population. Infection is mainly acquired by ingestion of food or water that is contaminated with oocysts shed by cats or by eating undercooked or raw meat containing tissue cysts. Primary infection is usually subclinical, but in some patients cervical lymphadenopathy, ocular disease, encephalitis, myocarditis, and pneumonitis can be present. By contrast with the favourable course of toxoplasmosis in almost all immunocompetent individuals, the disease can be lifethreatening in the immunocompromised ones. Toxoplasmic chorioretinitis, a common presentation in these individuals, may be seen in the setting of congenital or postnatally acquired disease as a result of acute infection or reactivation (4). Another severe presentation is the central nervous system involvement, classically described in the setting of AIDS (5) and also in the presence of corticosteroids and anti-TNF-alpha therapy $(6,7)$.

Adalimumab was the first fully human monoclonal antibody targeted against TNF-alpha. As other anti-TNF-alpha agents (etanercept and infliximab), it is licensed for the treatment of rheumatoid arthritis, psoriatic arthritis and ankylosing spondylitis (8). TNF inhibition has demonstrated effectiveness in the treatment of AS symptoms and all currently available anti-TNF agents appear to have similar efficacy (9).

More than 300.000 patients worldwide have been treated with adalimumab, which is commercially available in the US and 62 other countries (10), and so far, seems to be safe (11).

Anti-TNF-alpha agents can cause infections, malignancies, injection site reactions and others (1114). Tuberculosis is the most frequent opportunistic infection which has been reported with antiTNF-alpha therapy $(8,11)$.

We found a small number of reported cases of toxoplasmosis in patients using anti-TNF therapy: two cases of chorioretinitis (15) and two cases of cerebral toxoplasmosis $(6,7)$. Based on those cases, Lassoued et al raised the question of a link between toxoplasmosis infection and TNF-alpha antagonists therapy (15).

We did not found any description of acute toxoplasmosis in patients using adalimumab.

TNF-alpha plays an important role not only in inflammatory process, but also in the normal response against infections, and as a consequence, blocking this cytokine may increase risk of infectious complications (8). It is known that TNF-alpha has an important role specifically in protection against TG infections' playing a sinergycal role with IFN-gamma (16).

A study conducted by Chang et al revealed that mice treated for 8 days with recombinant murine TNF during infection with a virulent strain of TG were protected against the infection (16). In 1992, Johnson demonstrated that mice infected with a nonvirulent strain of TG developed infection and higher mortality when TNF-neutralizing antibod- 
ies were administrated. Although these evidences confirm that TNF is an important mediator of resistance to TG (17), there are few reported cases of toxopasmosis or other opportunistic infections in patients treated with anti-TNF-alpha therapy and specifically with adalimumab $(6,7,11,15)$.

TG infection has a wide range of manifestations, and its diagnosis can be difficult. General symp- toms like malaise, low-grade fever and visual complaints should prompt the investigation towards TG epidemiological and serological parameters. In this setting, an acute form of the disease or its reactivation could be present.

In addition, we suggest that adalimumab can be safely reintroduced after the complete resolution of an acute TG infection.

\section{SUMMARY}

We present a case of acute toxoplasmosis infection in a 36-year-old man with long-standing ankylosing spondylitis, treated with adalimumab. We review the association between antitumor necrosis factor therapy and toxoplasmosis. Our case illustrates that opportunistic infections may occur in patients treated with adalimumab, and emphasizes the importance of clinical suspicion and serological tests.

Parole chiave - Adalimumab, toxoplasmosi, spondilite anchilosante.

Key words - Adalimumab, toxoplasmosis, ankylosing spondylitis.

\section{REFERENCES}

1. Mansour M, Cheema GS, Naguwa SM, Greenspan A, Borchers AT, Keen CL, et al. Ankylosing spondylitis: a contemporary perspective on diagnosis and treatment. Seminars in arthritis and rheumatism 2007; 36: 210-23.

2. Frech T. Treatment of ankylosing spondylitis: focus on etanercept. Biologics 2007; 1: 45-51.

3. Sfikakis PP. The first decade of biologic TNF antagonists in clinical practice: lessons learned, unresolved issues and future directions. Curr Dir Autoimmun 2010; 11: $180-210$.

4. Montoya JG, Liesenfeld O. Toxoplasmosis. Lancet 2004; 363: 1965-76.

5. Liesenfeld O, Wong SY, Remington JS. Toxoplasmosis in the setting of AIDS. In: Bartlett JG, Merigan TC, Bolognesi D, eds. Textbook of AIDS medicine, 2nd edn. Baltimore: Williams \& Wilkins, 1999: 225-59.

6. Young JD, McGwire BS. Infliximab and reactivation of cerebral toxoplasmosis. N Engl J Med 2005; 353: 1530-1.

7. Gonzalez-Vicent M, Diaz Ma, Sevilla J, Madero L. Cerebral toxoplasmosis following etanercept treatment for idiophatic pneumonia syndrome after autologous peripheral blood progenitor cell transplantation (PBPCT). Annals Hematol 2003; 82: 649-53.

8. Toussirot É, Streit G, Wendling D, Minjoz J, Fleming B, Cedex FB, et al. Infectious Complications with Anti-TNF Diseases. Recent Pat Inflamm Allergy Drug Discov 2007; 1: 39-47.

9. Elewaut D, Matucci-Cerinic M. Treatment of ankylosing spondylitis and extra-articular manifestations in everyday rheumatology practice. Rheumatology 2009; 48: 1029-35.
10. Schiff MH, Burmester GR, Kent JD, Pangan aL, Kupper H, Fitzpatrick SB, et al. Safety analyses of adalimumab (HUMIRA) in global clinical trials and US postmarketing surveillance of patients with rheumatoid arthritis. Annals Rheum Dis 2006; 65: 889-94.

11. Burmester GR, Mease P, Dijkmans Ba, Gordon K, Lovell D, Panaccione R, et al. Adalimumab safety and mortality rates from global clinical trials of six immunemediated inflammatory diseases. Annals Rheum Dis 2009; 68: 1863-9.

12. Haroon N, Inman RD. Infectious complications of biological therapy. Current opinion Rheumatol 2009; 21 : 397-403.

13. Bongartz T, Sutton AJ, Sweeting MJ, Buchan I, Matteson EL, Montori V. Anti-TNF antibody therapy in rheumatoid arthritis and the risk of serious infections and malignancies: systematic review and meta-analysis of rare harmful effects in randomized controlled trials. JAMA 2006; 295: 2275-85.

14. Salliot C, Dougados M, Gossec L. Risk of serious infections during rituximab, abatacept and anakinra treatments for rheumatoid arthritis: meta-analyses of randomised placebo-controlled trials. Annals Rheum Dis 2009; 68: 25-32.

15. Lassoued S, Zabraniecki L, Marin F, Billey T. Toxoplasmic chorioretinitis and antitumor necrosis factor treatment in rheumatoid arthritis. Seminars Arthritis Rheum 2007;36:262-3.

16. Chang HR, Grau GE, Pechère JC. Role of TNF and IL1 in infections with Toxoplasma gondii. Immunology 1990; 69: 33-7.

17. Johnson LL. A protective role for endogenous tumor necrosis factor in Toxoplasma gondii infection. Infect Immun 1992; 60: 1979-83. 